\title{
Emotional Intelligence (EI) A Therapy for Higher Education Students
}

\author{
Robert P Machera ${ }^{1, *}$, Precious C Machera ${ }^{2}$ \\ ${ }^{1}$ Department of Accounting and Finance, Faculty of Business and Accounting, University: Botho University, Botswana \\ ${ }^{2}$ Department of Finance and Banking, Faculty of Business and Accounting, Imperial School of Business and Science College, Botswana
}

Copyright $(2017$ by authors, all rights reserved. Authors agree that this article remains permanently open access under the terms of the Creative Commons Attribution License 4.0 International License

\begin{abstract}
This study investigates the need to design and develop emotional intelligence curriculum for students in higher education. Emotional intelligence curriculum may be used as a therapy that provides skills to manage high emotions faced by generation "Y", on a day to day basis. Generation " $Y$ " is emotionally challenged with: drug abuse, family abuse, sexual abuse, and relationship problems and other challenges. This curriculum assists students to boost their own emotional intelligence by learning how to cope with stresses. The module intends to promote emotional intelligence quotient in future graduates. The skills and techniques for emotional intelligence may be developed throughout someone's life as part of lifelong learning and would form the foundation for a balanced lifestyle. This study investigates to what extend students in higher education are presently exposed to emotional intelligence techniques as part of their curriculum. A survey and a qualitative approach were used to gather data from the students at Botho University who are enrolled in the Bsc Hons in Accounting. The results informed the researchers whether higher education should introduce a curriculum for emotional intelligence.
\end{abstract}

Keywords Emotional Intelligence, Therapy, Society, Stress, Relationship, Students, Generation "Y"

\section{Introduction}

In any educational set up students in higher education interact within their communities and they face many emotional challenges. It is from this background that the researchers were motivated to conduct this study on emotional intelligence. However, one would ask why emotional intelligence? [6] postulated that emotional intelligence is about productivity and performance. Emotional intelligence can be developed and measured. Emotional intelligence is about sustainable that change enhances human behaviour [8]. In the context of this study emotional intelligence act as a therapy that reduces high emotions. The $21^{\text {st }}$ century students in this study are referred as Generation "Y". Generation $Y$ is exposed to a lot of emotional challenges which requires higher educators to address or correct some of the behaviour in order to boost academic performance. Students in higher education are taught specific courses and there is a gap in terms of soft skills module such as emotional intelligence. Therefore it is imperative to introduce an emotional intelligence module to close the gap between academic subjects and the soft skill subjects. The more the students learn about reducing high emotions the more they perform better in their academic subjects. The skills for emotional intelligence may be developed throughout someone's life as they are part of lifelong learning and this form the foundation for a balanced lifestyle. This study investigated to what extent students in higher education would be exposed to emotional intelligence techniques as part of a curriculum. The results of this research informed the researchers that there was a need to develop, design and introduce a curriculum for emotional intelligence in higher education.

\subsection{Conceptual \& Theoretical Framework}

This study included the concept to understand emotional intelligence through the study of how human brains work. The evolved human brain may be split into three different parts and this is known as [4]'s triune brain model. The triune brain model is shown in figure 1 below. 


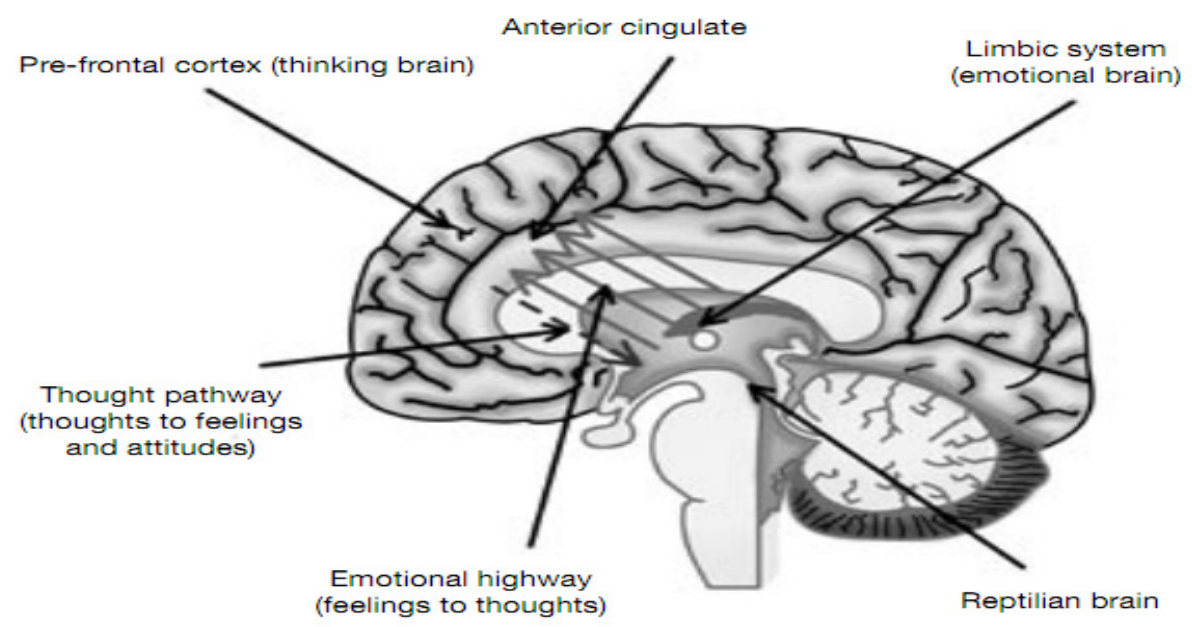

Figure 1. Paul MacLean`s triune brain model (1973) adapted from Neale, Arnell and Wilson (2009:5).

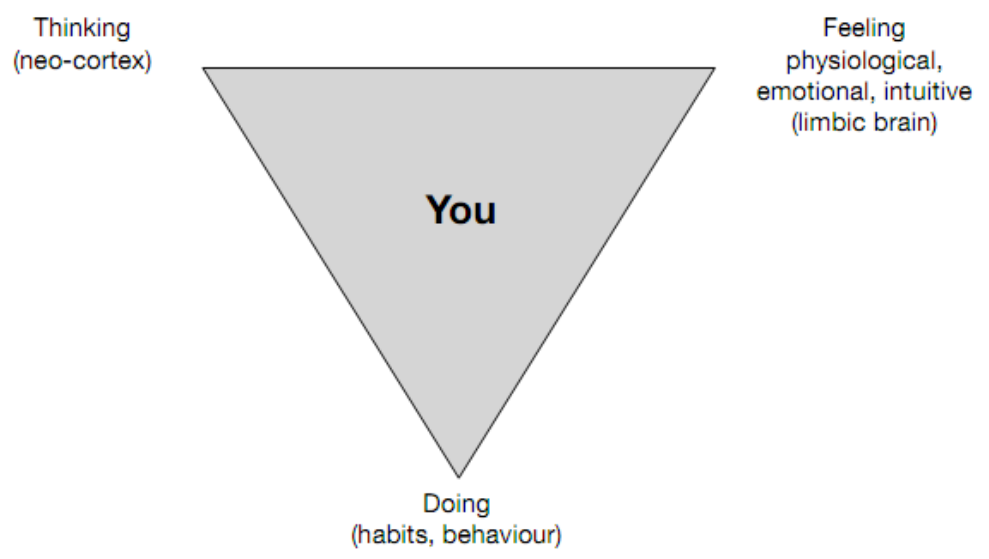

Figure 2. Thinking, feeing doing triangle adapted from Neale, Arnell and Wilson (2009:5)

\subsection{Paul MacLean's Triune Brain Model (1973)}

Emotions are primarily about attitude, first we make our attitudes and then our attitudes make us [2]. This involves the experiential triangle of thoughts, emotions and actions. Whatever the situation people are always thinking, feeling and doing, these three things are connected [6]. This is consistently how human brains work. See figure 2 which shows the connection between thinking, feeling and doing.

The generation "Y" develops hundreds of attitudes / perceptions about the world around them, mostly based on their experiences and what they are taught by peers and adults. Attitudes play a vital role in how human beings react to things emotionally and then result in an act which is either positive or negative. The following section focuses on the problem statement of this study.

\section{Statement of the Problem}

Generation " $Y$ " is emotional challenged with: drug abuse, family abuse, sexual abuse, relationship problems and other challenges. These challenges affect the students' academic performance and as a result most of the students fail to finish their enrolled courses. There are a number of drop-outs at tertiary institutions as a result of high emotions. The behaviour and negative attitudes for students in higher education require a therapy such as emotional intelligence techniques. Emotional intelligence reduces high emotions and increase productivity. Therefore a module on emotional intelligence would assist Generation " $\mathrm{Y}$ " in controlling emotions hence the need for this soft skill module.

\section{Aim of the Study}

To investigate the need to design, develop and introduce emotional intelligence curriculum to students in higher education.

\section{Objectives of the study}

The objectives of this study are as follows: 
1. To ascertain whether students at Botho University are emotional challenged

2. To identify the techniques that assist to reduce high emotions

3. To identify whether there is a relationship between emotional intelligence and academic performance

\section{Research Questions}

The following are the research questions for this study:

1. To what extent are students in higher education emotionally challenged?

2. What techniques are used to reduce high emotions?

3. What is the relationship between emotional intelligence and academic performance?

\section{Contribution to the Knowledge Domain}

The significance of this study is that, it would benefit different stakeholders including lecturers, students, universities and colleges. The universities and colleges would then be able to achieve higher pass rates. Additionally the introduction of the emotional intelligence module may assist in reducing the drop-out rates. If this study is published it would add to the body of knowledge as it improves the academic performance of the students.

\section{Literature Review}

This section of focuses on the literature review underpinning emotional intelligence.

\subsection{What is Emotional Intelligence?}

According to [7] emotional intelligence refers to the ability to perceive, control and evaluate one's emotions and other individuals' emotions. Emotional intelligence is a process of controlling one's emotions or feelings [7]. However, [7] proposed a model which identified four different factors for emotional intelligence, perceiving emotions: reasoning with emotions, understanding emotions and managing emotions. The following section explains the four factors that were identified by Salovey.

\subsection{Perceiving Emotions}

The first step when dealing with emotional intelligence is to understand emotions and accurately perceive them [7]. The way to understand emotions is through nonverbal signals such as body language and facial expressions. It is imperative to observe the body language in different situations. Martha Graham the US dance choreographer (1894-1991) quotes that "The body says what words cannot". The body language may portray the attitude of an individual.

\subsection{Reasoning with Emotions}

The next step in the process of understanding emotions is to promote thinking and cognitive activity [6]. The step helps to prioritize and pay attention on what to react on first. Human beings respond emotionally to things that garner their attention.

\subsection{Understanding Emotions}

The emotions that human beings perceive can carry a wide variety of meanings [6]. Therefore, if an individual is expressing angry emotions, the observer must interpret the cause of the person's anger and what it might mean. For example if the manager is acting angry, it may be perceived that the employee's work dissatisfied the manager; or the manager might have been involved in an argument with someone. Therefore emotional intelligence assists individual to analyse high emotions and deal with them in a calm manner.

\subsection{Managing Emotions}

This is the ability to manage emotions in an effective manner and is a key part of emotional intelligence [6]. This is known as emotional management, which is a process of regulating emotions and responding appropriately to the emotions of others. The following section focuses on the levels of emotions.

\subsection{Understanding Levels of Emotions}

Individuals should be able to understand the levels of emotions at all the times as shown on the levels of emotion on figure 3 below. 


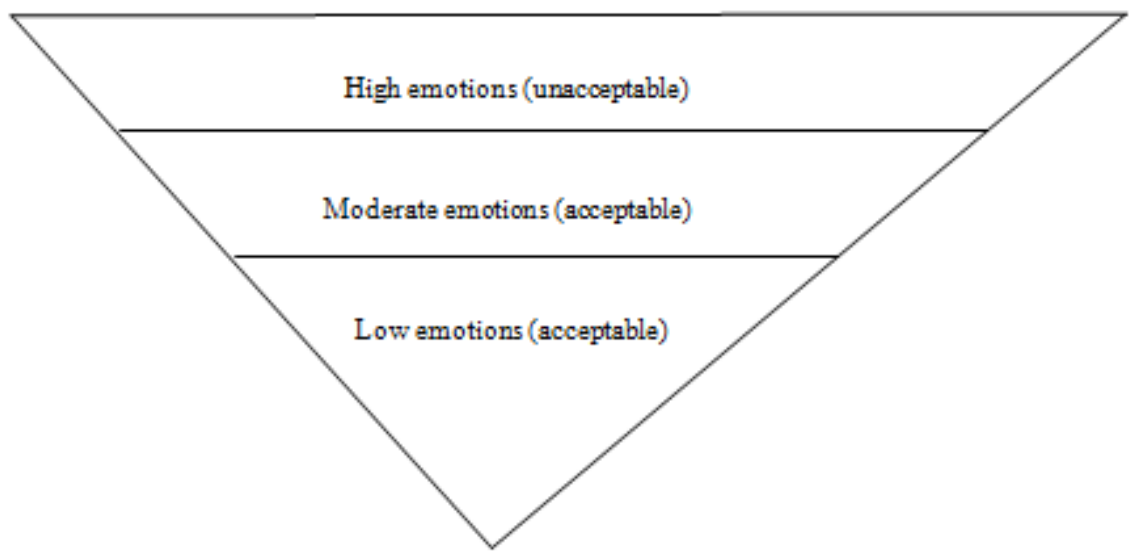

Figure 3. Categories / levels of emotion adapted from researchers (2016)

Emotions are acceptable if there are low and an individual is calm. It is imperative to make informed decisions at this level. Emotions are moderately acceptable when an individual is at this level but it is recommended to reduce this to the low level. High emotions are not acceptable and individuals should not make decisions when charged at this level. It is important for human beings to understand and diagnose the levels of emotions in order to make informed decisions. The following section focuses on the emotional intelligence skills.

\subsection{Emotional Intelligence Skills}

There are four core emotional intelligence skills that enhance people in managing emotions and behaviour: relationship management: self - esteem: decision making and stress management.

\subsection{Relationship Management}

The halo and horn effect model developed by [7], assist human beings in how they relate to each other. The halo and horn effect help people to manage their subordinates and colleagues. Halo effect is whereby an individual connects very well with another and the horn is a situation whereby there is no connection at all. The two effects help people when communicating in situations which they are highly charged. Maintaining good relations help individuals to communicate well with others as this boosts morale and productivity.

\subsection{Self - esteem}

There are three levels of self - esteem: low esteem, moderate esteem and high esteem. With low esteem the individual is not able to control high emotions. However, moderate and high esteem individuals are better able to control high emotions. Therefore it is always recommended to have a high self - esteem. The advantages for self - esteem growth are that one will gain control over emotions: the level of stress will decrease: the person increases the level of relaxation: the person feels motivated and energetic: the person is able to handle conflict appropriately and develop new good habits.

\subsection{Decision Making}

An understanding of emotional intelligence assists individuals to be proactive rather than to wait for crisis to manage their situations. The person develops a technique of applying a soft character or hard character depending on the circumstances surrounding the situation. Individuals would be able to use the $\mathrm{X}$ and $\mathrm{Y}$ theory for Douglas McGregor [7].

\subsection{Stress Management}

Stress management is an emotional intelligence skill that assists individuals to realise that they are stressed and the appropriate manner on how to respond. The individuals are able to discover the stress strategy that works for themselves, especially the four senses for example: sense of sound: smell, taste and touch. Individuals develop a positive attitude for stress tolerance. When applying this technique individuals can utilise optimism to see threat as an opportunity rather than a setback.

\subsection{Therapy for emotional intelligence}

Individuals may boost their own emotional intelligence through [7]:

- Utilising good nonverbal communication: eye contact: facial expression: tone of voice and posture and gesture

- Using humor and laughter

- Seeing work as play (Douglas McGregor's ' $Y$ ' theory)

- Staying focused

- Choosing / selecting the right words

- Learning to forgive

- Finding strategies to reduce high emotions (take a walk, do shopping, watch cartoons, gardening and any other activities besides formal working) 


\section{Research Methodology}

According to [5] a research design is a plan which explains how a research would be conducted. In this study a quick survey was used to collect data from the participants. Questionnaires were distributed to students enrolled for the Bsc Hons in Accounting at Botho University. The population was 215 students studying Financial Accounting Module in 2015 for semester four at Botho University. The researchers distributed 120 questionnaires and 96 students managed to complete the questionnaires. The questionnaires included questions that followed the Likert point system and the last questions were qualitative in nature. The qualitative types of questions were necessary in order to enhance the validity and reliability of the study. In order to eliminate bias on the findings the questionnaires were analysed by an independent person but the results were interpreted by the researchers. The results were analysed using excel spreadsheet, charts and graphs. The following section focuses on the ethical considerations.

\section{Ethical Considerations}

The researchers did not plagiarise, or fabricate or falsify evidence or knowingly misrepresenting information or its source [1]. The researchers received to get the students' consent to participate. [3] argue that protecting individual autonomy has long been a central principle in educational research; therefore the researchers did not coerce any student to participate in this study. Furthermore the researchers did not divulge any information to third parties as this would be an infringement of the participants' rights to privacy. Finally original or actual names were not used in this study.

\section{Results / Findings of the Study}

The following were the results that were analysed based on the survey, mentioned in section 9 above. The results below reflect the percentage of males and females who participated in this study. The research maintained a balance between females and males who participated in this study in order eliminate gender biasness from the findings. Table 1.1 below shows the number of male and female students who participated in this study.

Table 1.1. Gender for participants

\begin{tabular}{|c|c|c|c|}
\hline Gender & Module / Subject & Number & Percentage \\
\hline Males & Financial Accounting & 35 & $41 \%$ \\
\hline Females & Financial Accounting & 51 & $59 \%$ \\
\hline Total & Financial Accounting & 86 & $100 \%$ \\
\hline
\end{tabular}

The following figure 4 represents the respondent according to gender. In the Botswana context the following percentages 41 and 59 for males and females respectively are acceptable as there are more women than man.

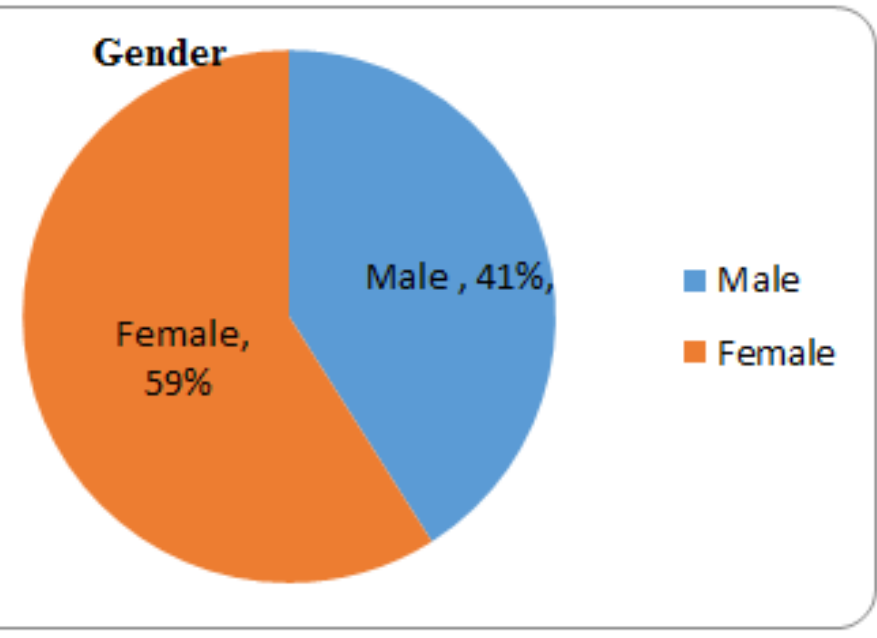

Figure 4. Gender for participants 


\subsection{Am Stressed to Due to Lack of Financial Support?}

The results indicated that $75 \%$ of the respondents were stressed due to lack of financial support. This shows that the students required high level of counselling. Through practical activities which are embedded in the module for emotional intelligence. The following figure 5 shows the percentages for the respondents to the above question.

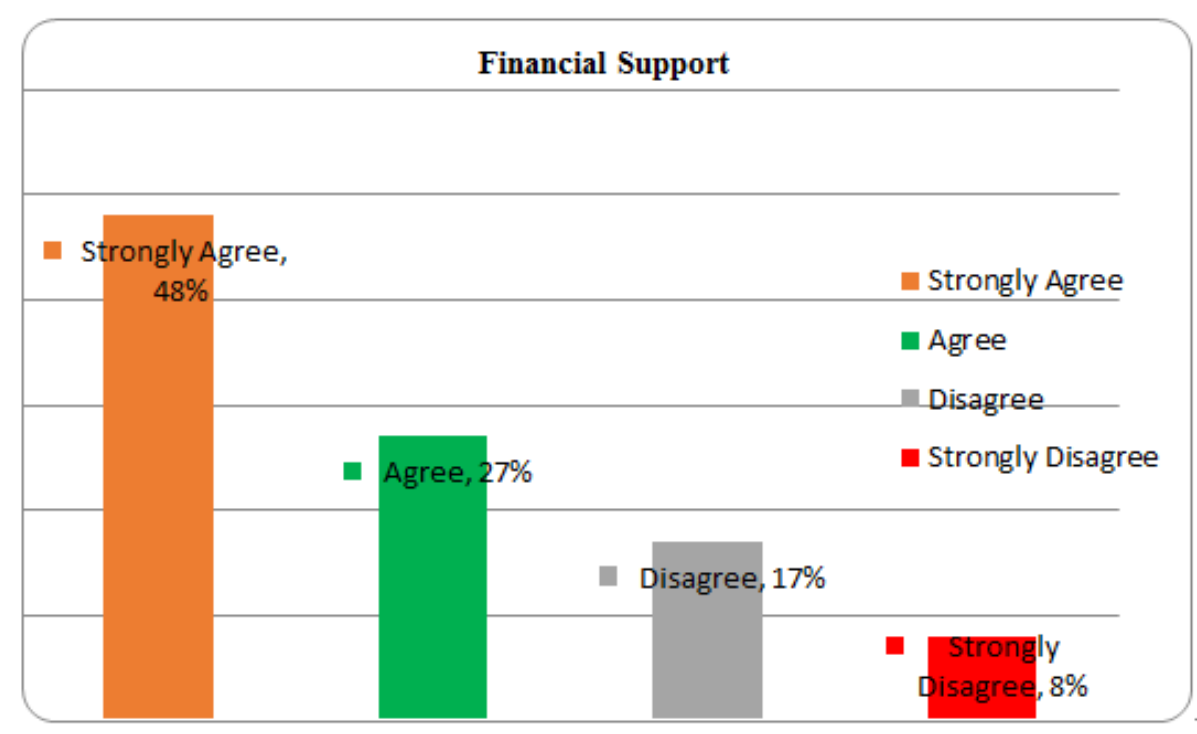

Figure 5. Financial Support

\subsection{Need a Module That Helps Me to Control My Emotions?}

The results reflected that $69 \%$ of the respondents strongly agreed and agreed that they need a module that helps them to control their emotions. The following figure 6 shows how the participants responded to the above question.

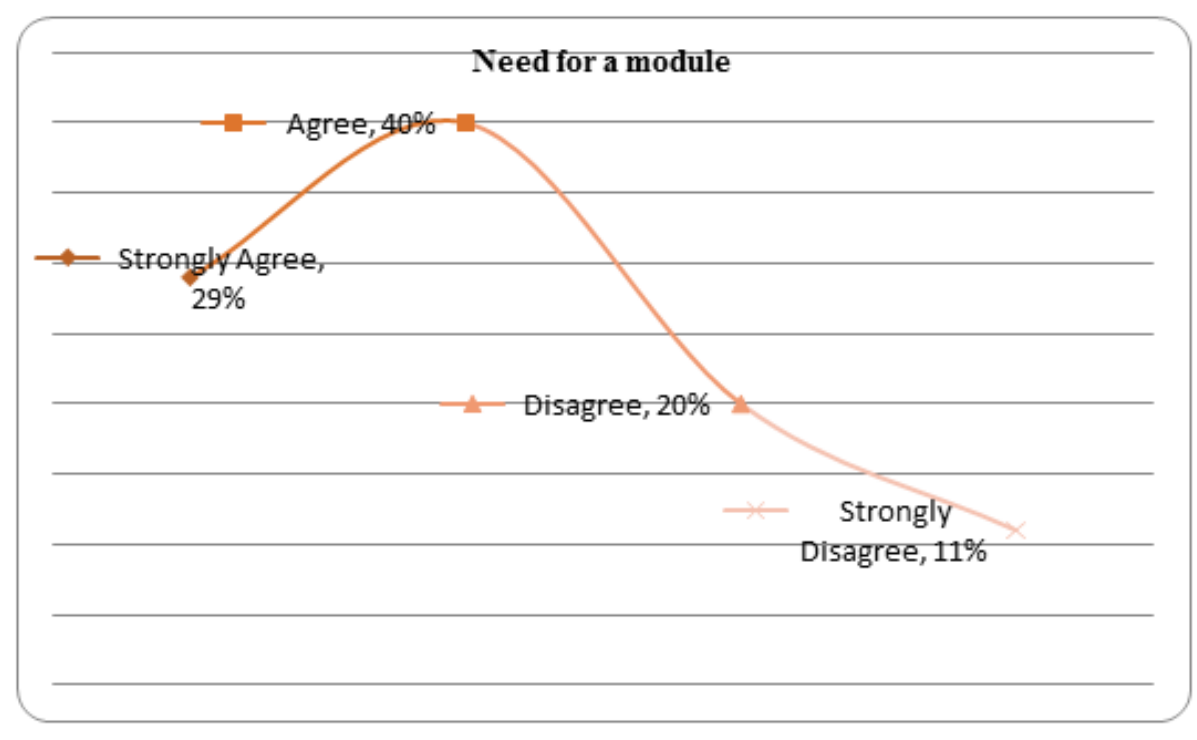

Figure 6. Need for a Module

\subsection{Tertiary Students Must Control Their Emotion?}

The results on figure 7 show that $93 \%$ of the respondents strongly agreed and agreed that tertiary students must control their emotions. These results reflect the symptoms for potential problems with attitude and behaviour that affects students' performance in higher education. In any educational setting good academic performance enhances the economic growth and wealth of the country. The following figure 7 shows how the responses for the participants to the above question. 


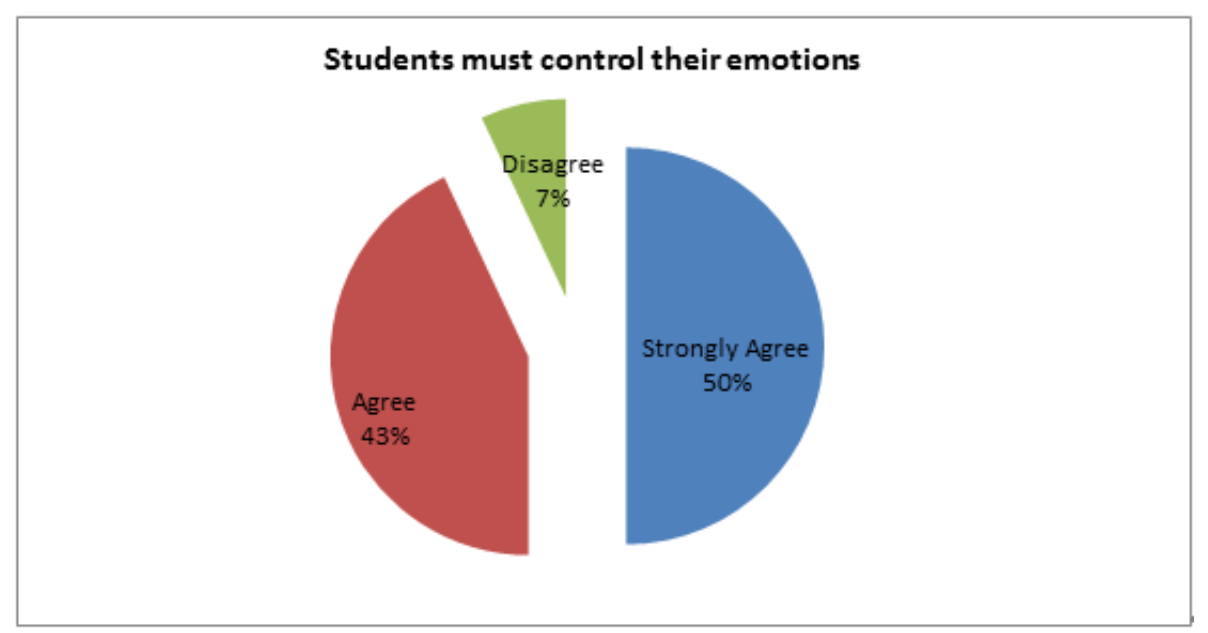

Figure 7. Students must control their emotions

\subsection{Higher Education Students May Be Emotionally Challenged with: Drug Abuse, Family Abuse, Sexually Abuse and Society Abuse?}

The results reflected that $95 \%$ of the participants strongly agreed that higher education students were emotionally challenged with: with drug abuse, family abuse, sexually abuse and society abuse. This shows that students are human beings and are sensitive to their relationships and surroundings.

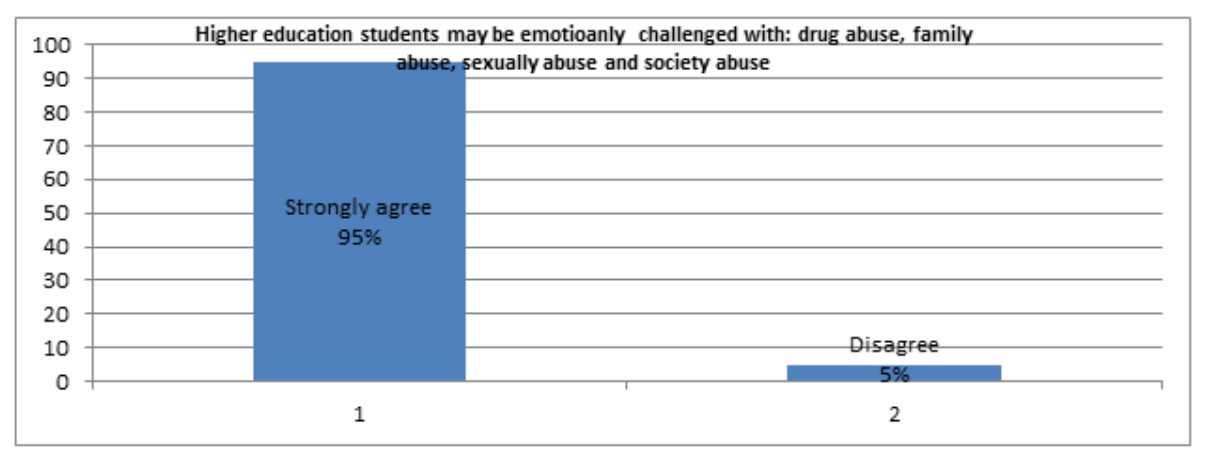

Figure 8. Higher education students may be emotionally challenged with: drug abuse, family abuse, sexually abuse and society abuse?

\subsection{Tertiary Students May Be Emotionally Challenged?}

The results indicated that $86 \%$ of the participants strongly agreed and agreed that tertiary students were emotionally challenged. Based in these results it shows that the module for emotional intelligence may act as a therapy in higher education. The following figure 9 shows how the participants responded to the above question.

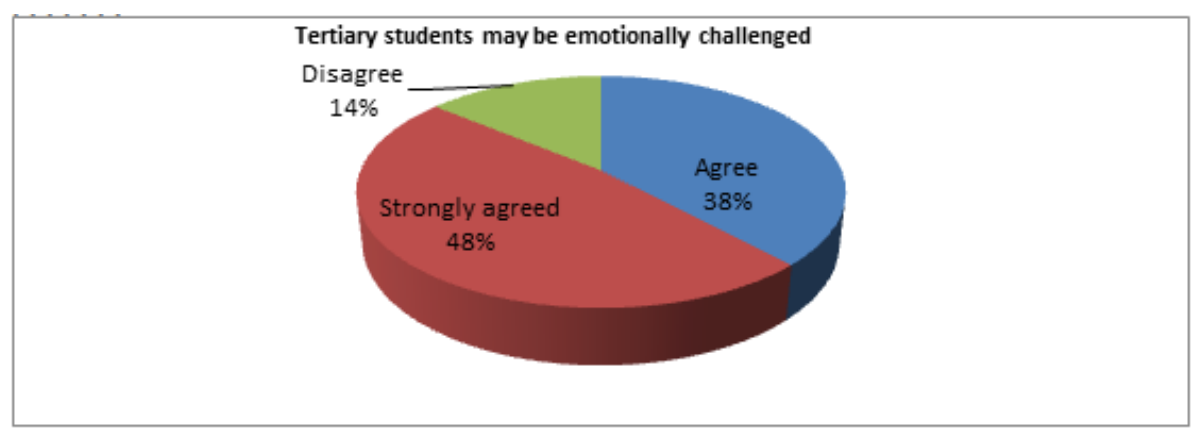

Figure 9. Tertiary students may be emotionally challnged? 


\subsection{Higher Education Students May Encounter Conflict with Peer, Lecturers and Other Members of the Society?}

The results reflected that $92 \%$ of the respondents strongly agreed and agreed that higher education students encounter conflicts with peer, lecturers and other members of the society. Therefore this module may act as the intermediator between the students, society and higher education institutions. The results to the above question were shown on figure 10 below.

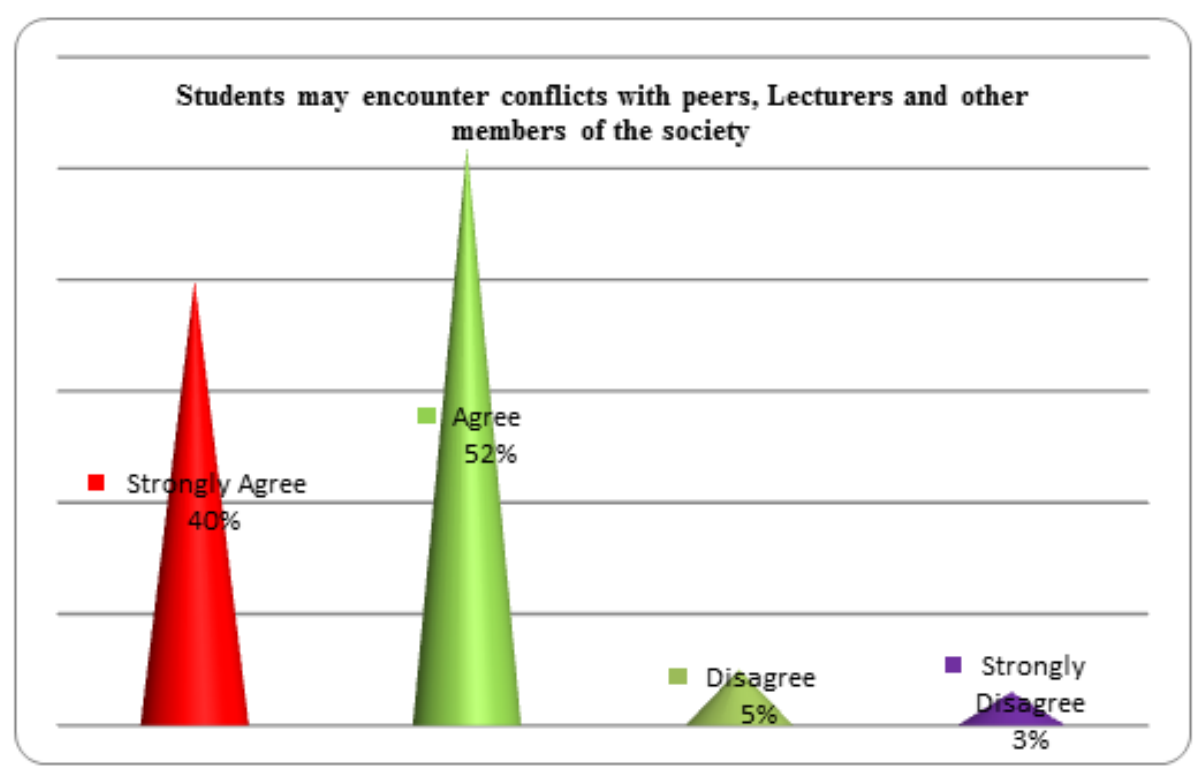

Figure 10. Students may encounter conflicts with peers, lecturers and other members of society

\subsection{Higher Education Students May Get Disturbed after Failing an Examination?}

The results indicated that $98 \%$ of the respondents agreed that higher education students felt disturbed after failing an examination. Therefore the module for emotional intelligence may assist students after failing examination. See the results on figure 11 below.

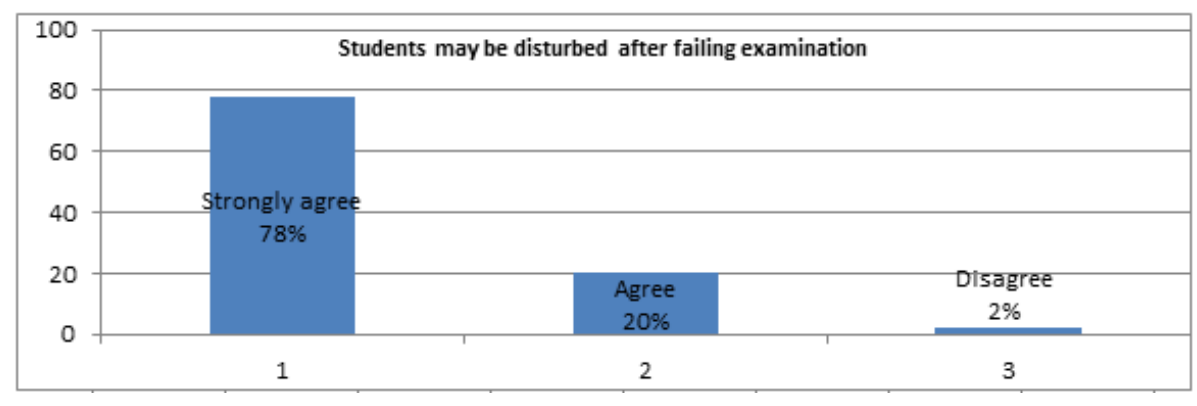

Figure 11. Students may get disturbed after failing examination

\subsection{Higher Education Students May Get Excited after Passing Examination?}

The results reflected that $94 \%$ of the respondents strongly agreed and agreed that higher education students get excited after passing examination. The findings show that the students after getting excited they become over confident and their next results would be affected. Therefore the emotional intelligence module would assist students to calm down and stay focused. The following figure 12 shows how the participants responded to the above question. 


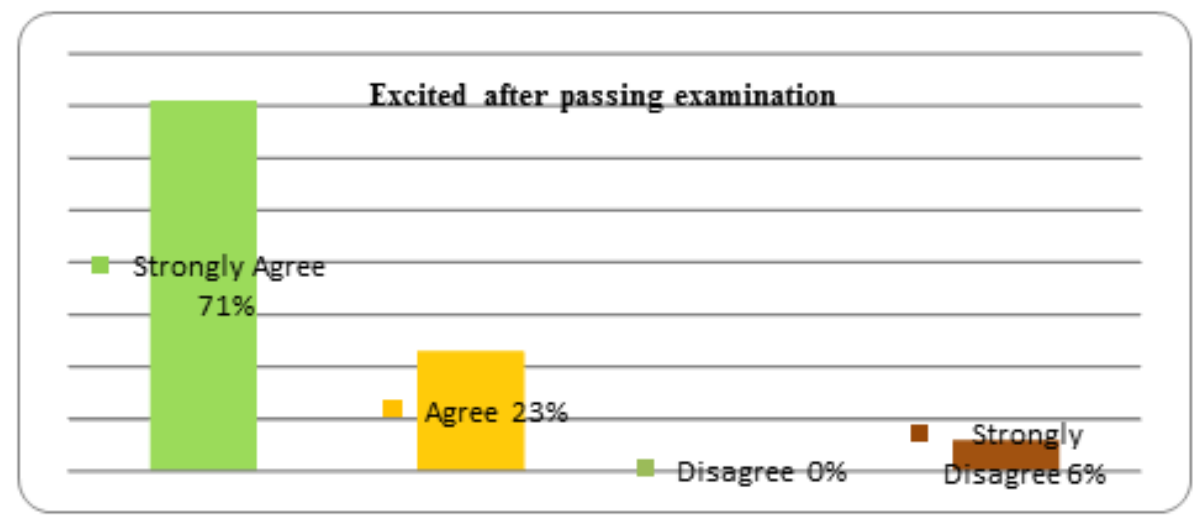

Figure 12. Excited after passing examination

\subsection{Female Tertiary Students May Indulge in Unwanted Pregnancies?}

The results reflected that $85 \%$ of the participants strongly agreed and agreed that female tertiary students indulged in unwanted pregnancies. This shows that the students require high level of discipline and this unbearable behaviour may be corrected through the introduction of the emotional intelligence module. The figure 13 below shows how the responses to the above question.

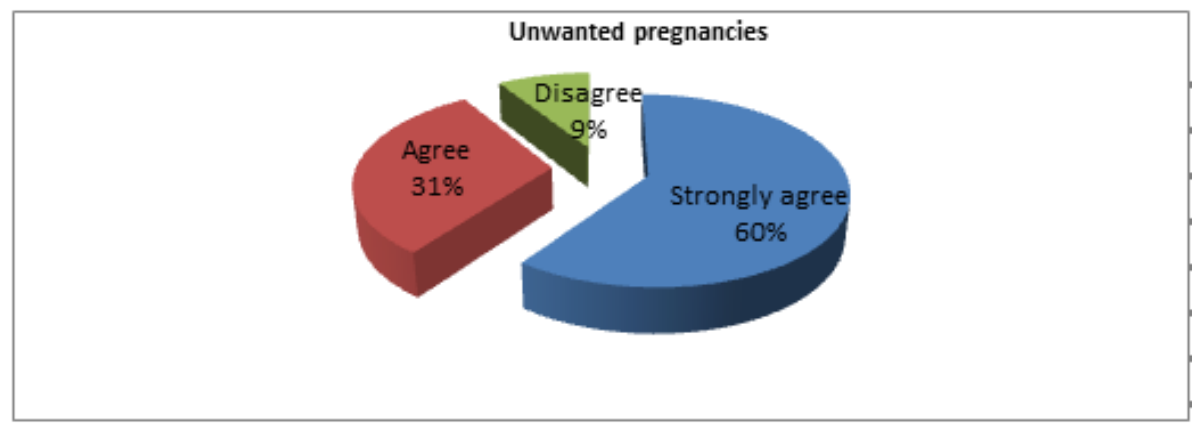

Figure 13. Unwanted pregnancies

\subsection{Higher Education Students May Contact Sexually Transmitted Diseases?}

The results on figure 14 indicated that $90 \%$ of the participants strongly and agreed that higher education students may contract sexually transmitted diseases. Therefore it is in this forum where students may be exposed to the real - world. The results were shown on figure 14 below.

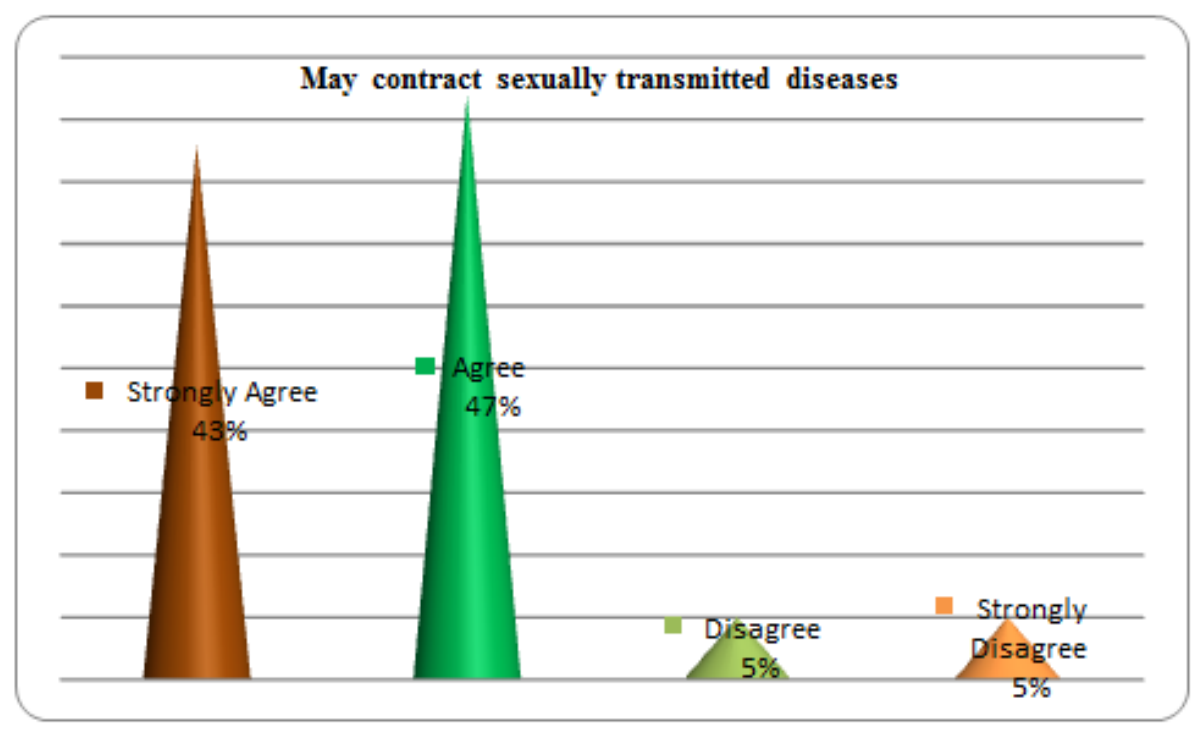

Figure 14. May contract sexually transmitted diseases 


\subsection{Higher Education Students May Be Involved in Prostitution, Gangsters and Unprotected Sex?}

The results reflected that $84 \%$ of the participants strongly agreed and agreed that higher education students were involved in prostitution, gangsters and unprotected sex. The introduction of the emotional intelligence may assist students in correcting this negative attitude. The results were shown below on figure 15 .

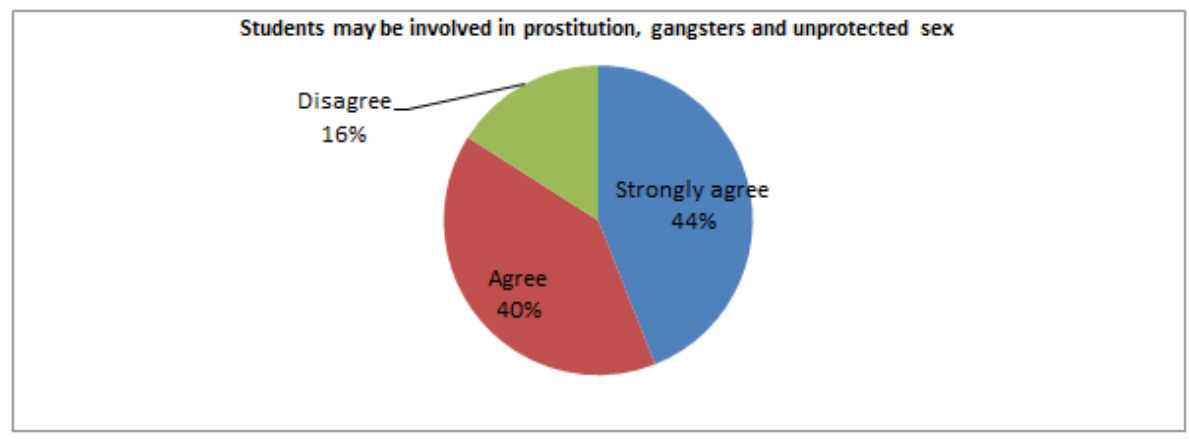

Figure 15. Students may be involved in prostitution, gangsters and unprocted sex

\subsection{Higher Education Students Require a Module That Helps Them to Reduce and Manage Stress?}

The results reflected that $83 \%$ of the participants strongly agreed and agreed that higher education students required a module that helps them to reduce and manage stress. Therefore this module may act as a therapy that addresses the students' behaviour and attitudes. The results for the above question are shown on figure 16 below.

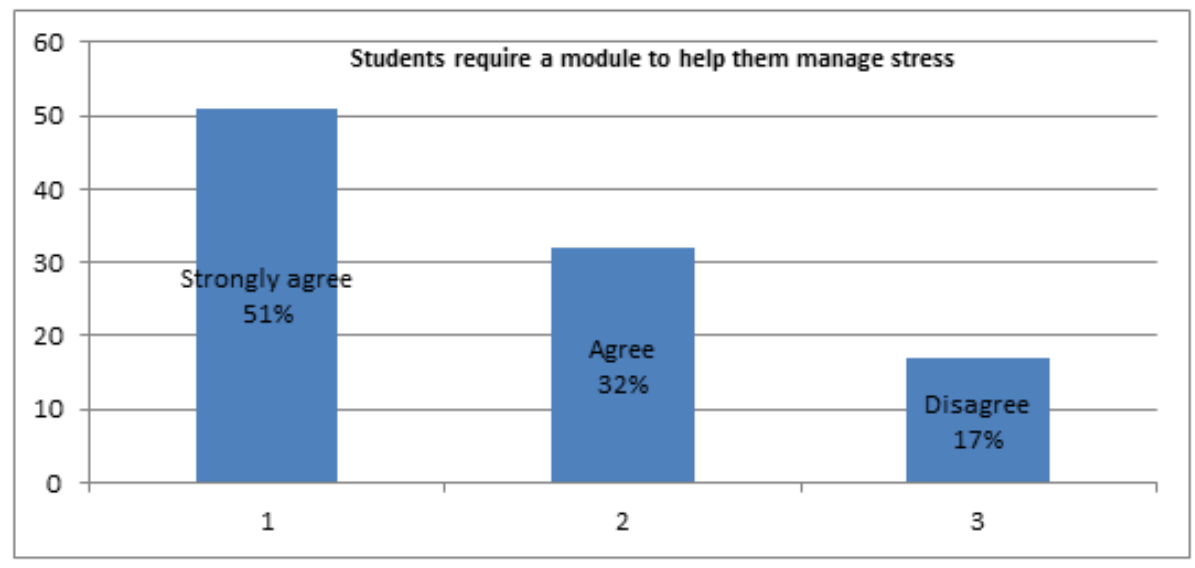

Figure 16. Students require a module to help them manage stress

The following section focuses on the qualitative results of this study.

\subsection{Qualitative Results}

Comments from the students about the emotional intelligence module:

- Most of the students highly appreciated the proposal to introduce the module

- The students felt that it was very helpful to the since they were emotionally challenged

- The students agreed introduction of this module as long it was not examined

- The students highlighted that this module would address bad things like prostitution and unprotected sex as they become focused

- The students felt that the module would help them to balance academic life and real life.
- Students felt that they face a lot of emotional problems and the module would be so helpful to them.

- The students felt that the module may have a positive influence in individual's academic performance and productivity.

\section{Conclusions}

The results above reflected that it was imperative to introduce a module on emotional intelligence in higher education. This module assists students in correcting their negative behaviour and attitudes. Therefore, if this module is implemented well the academic performance in higher education especially at Botho University may improve. The 
more positive the results the greater the reduction drop outs and hence this may influence the growth of the university. The following were recommendations given if this module would be introduced:

\section{Recommendations}

- Conduct workshops with the students so that they understand the implications of introducing the module

- Seek approval from Botho University Senior Management before implementation

- If the module is approved by Senior Management, submit for accreditation with Botswana Qualification Authority

- Pilot the implementation of the module first before introducing it

- The assessments for this module should be practical

- The teaching methodology should include: videos, case study, role play and establish an emotional intelligence club

- The module should be lifelong learning as long students are still enrolled at Botho University

- Source books, videos journals, articles and register with psychology trainers

- Training of facilitators for the emotional intelligence module

- Encourage road show emotional intelligence awareness in all the centres

\section{REFERENCES}

[1] American Anthropological Association. 2012. Statement on Ethics: Principles of Professional Responsibilities. Available: http:// www.aaanet.org/coe/Code_of_Ethics.pdf. [2015, 22 January]

[2] Goleman, D. 1996. Emotional Intelligence: Why it can matter more than $I Q$, Bantam Books, London.

[3] Lucas, K., B. and Lidstone, J, G. (2000). Ethical issues in teaching about research eth1ics. Evaluation and Research in Education 14 (1): 51-72.

[4] MacLean, P., D. 1973. The Triune Brain in Evolution: Role in paleocerebral functions, Plenum Press, New York.

[5] Mouton, J. (2001). How to succeed in your Master's \& Doctoral Studies: A South African Guide and Resource Book. Pretoria: Van Schaik.

[6] Neale, S. Arnell, S., L. and Wilson, L. 2009. Emotional Intelligence Coaching. Replika Press Pvt Ltd: London. United Kingdom.

[7] Salovey, P. and Mayer, J. 1990. Emotional intelligence. Imagination, cognition and personality 9 (3): $185-211$.

[8] Thorndike, R., L. and Stein, S. 1937. An evaluation of the attempts to measure social intelligence. Psychological Bulletin 34 (1): 275 -284. 